Article

\title{
Experimental Analysis on Dynamic Responses of an Electrical Platform for an Offshore Wind Farm under Earthquake Load
}

\author{
Zhen-Zhou Sun ${ }^{1}$, Chun-Wei Bi ${ }^{2, *}$, Sheng-Xiao Zhao ${ }^{1}$, Guo-Hai Dong ${ }^{2}$ and Hua-Feng Yu ${ }^{1}$ \\ 1 Power China Huadong Engineering Corporation Limited, Hangzhou 310014, China \\ 2 State Key Laboratory of Coastal and Offshore Engineering, Dalian University of Technology, \\ Dalian 116024, China \\ * Correspondence: bicw@dlut.edu.cn
}

Received: 29 June 2019; Accepted: 15 August 2019; Published: 18 August 2019

\begin{abstract}
Offshore wind power is gradually developing to more open sea. Considering the economy of power transmission, it will be an inevitable choice to adopt the extra-large electrical platform. The offshore electrical platform is easily affected by sudden extreme loads such as earthquake and high current loads. With a large volume of electrical equipment arranged on the deck, the offshore electrical platform is characterized as a top-heavy structure in the offshore wind farm. The dynamic effect of the structure will aggravate the vibration problem of the structure. In this paper, a physical model test was carried out to study the dynamic characteristics of the electrical platform of a 10,000-ton offshore converter station under seismic load. The acceleration response, displacement response and stress response of the offshore electrical platform under the typical direction of seismic action were obtained. The effect of the dry-wet environment, mode of seismic excitation, whipping effect and weak positions of electrical platform structure were analyzed. It was determined that the average damping ratio of the first-order mode of the electrical platform was $5.73 \%$ and $8.68 \%$ with and without water, respectively. The bidirectional seismic excitation was more dangerous to the structure than unidirectional excitation. The peak acceleration along the height of the platform showed a typical whipping effect.
\end{abstract}

Keywords: offshore electrical platform; dynamic response; earthquake load; laboratory experiment

\section{Introduction}

Wind power is the main form of wind energy utilization. Due to low cost, eco-friendly and significant benefits, wind power has drawn the world's attention as the fastest developing new energy with great potential. In recent years, the attention of the world wind power industry gradually turns to offshore wind power. Offshore wind farms, which initially invest several times more than onshore wind farms, have better wind resources because they are not affected by site and power limitations. Therefore, an offshore wind farm is far more profitable than an onshore one during the operating period of the project. At present, the offshore wind power is gradually developing to more open sea $[1,2]$. Considering the economy of power transmission, it will be an inevitable choice to adopt the extra-large electrical platform, such as offshore converter station, for the large-scale offshore wind power development in the future. The structure of offshore electrical platform is complex, especially under the combined action of loads caused by wind, wave, current and other environmental factors, and threatened by sudden extreme loads such as typhoon and earthquake. In addition, with a large volume of electrical equipment arranged on the deck, the offshore electrical platform is characterized as a top-heavy structure in the offshore wind farm. The dynamic effect of the structure will aggravate 
the vibration problem of the structure. The choice of the platform type is related to the structure weight, the geological condition and the marine hydrological parameters. When the total weight of the superstructure is less than $1000 \mathrm{t}$, single-pile foundation is usually adopted, while gravity foundation can be used when the geological conditions are good and the water depth is relatively shallow. However, when the water depth is large and the total weight of the superstructure exceeds $1000 \mathrm{t}$, jacket foundation should be considered. Most offshore wind farm and oil platform are located in the edge of the continental plates. Thus, a strong earthquake is one of the main fracture loads of marine engineering structures. A strong earthquake could lead to very serious damage, studies on seismic responses and collapse analysis of the offshore electrical platform is very necessary [3-5].

In recent years, scholars have carried out a lot of theoretical and experimental research on the structural response of fixed offshore platforms under seismic load. For design specifications for offshore platforms under seismic conditions, Bea et al. [6] analyzed the seismic response of the traditional steel jacket platform under strong earthquakes, and verified that American Petroleum Institute (API) related specifications for the design of an offshore platform structure could guarantee the offshore platform structure to have good anti-seismic performance. Chandrasekaran and Gaurav [7] analyzed the dynamic behavior of a triangular tension leg platform under distinctly high sea waves in the presence of both horizontal and vertical seismic excitations. Huang and Foutch [8] studied the effect of hysteresis models on the global collapse drift limit, seismic demand and capacity/demand ratio for moment resisting frame (MRF) structures under seismic loads. Yu et al. [9] developed a transient dynamic analysis method to study the dynamic characteristics of a jack-up platform in regular and random waves. Araki and Hjelmstad [10] proposed criteria for assessing the propensity for dynamic collapse of an elastoplastic structural system. Salem et al. [11] assessed the response modification factor of open steel platform subjected to seismic loads using both nonlinear static pushover analysis and nonlinear dynamic time history analysis. Besides, there are a number of studies on the dynamic characteristics of wind turbine under seismic load. Failla et al. [12] studied the effects of response-spectrum uncoupled analyses on seismic assessment of offshore wind turbine. Zhao et al. [13] conducted a fully coupled time domain simulation to investigate the dynamic characteristics of an ultra-large semi-submersible offshore wind turbine in typical sea states. Prowell et al. [14] carried out shake table tests on an actual wind turbine in both parked and operational conditions with parallel and perpendicular orientations of shaking direction. Zheng et al. [15] performed a series of shake table model tests of a monopile wind turbine foundation in dry flume, low and high calm water levels, with and without regular or random waves. Wang et al. [16] conducted both a physical model test and numerical analysis of a multi-pile offshore wind turbine under seismic, wind, wave and current loads. Sadowski et al. [17] presented an analysis of the seismic response of a steel support tower of the wind turbine modeled as a near-cylindrical shell structure with realistic axisymmetric weld depression imperfection. Wang et al. [18] developed an integrated analysis model to analyze the dynamic characteristics of a bottom-fixed offshore wind turbine under earthquakes. Although there are many researches on the dynamic response of the jacket platform and wind turbine, the research on the dynamic characteristics of this kind of top-heavy electrical platform under the earthquake load has not been reported.

The electrical platform in the offshore wind farm bears a volume of electrical equipment arranged on each deck. For the offshore converter station platform in open sea, the environmental loads such as wind, wave, current and earthquake acting on the overall structure are complex alternating and fluctuating loads, which are likely to gradually stimulate and form excessive vibration response. Coupled with the large size and weight of the upper block of the converter station, the platform is a typical top-heavy structure. The dynamic effect of the upper structure may aggravate the vibration problem of the structure. In this paper, a physical model test is carried out to study the dynamic characteristics of the electrical platform of a 10,000-ton offshore converter station under seismic load. 


\section{Materials and Methods}

\subsection{Experimental Model Design}

Based on the hydroelastic similarity and the previous experiences on the physical model test, plexiglass was selected as the material for the experimental model [16]. In order to obtain the basic material parameters of plexiglass, the mechanical test was carried out for the selected plexiglass, which was used to make the experimental model. According to the results of the mechanical test, the density of plexiglass material used in the test model was $1201 \mathrm{~kg} / \mathrm{m}^{3}$, the static elastic modulus was 2.62 GPa, the Poisson ratio was 0.42 and the dynamic modulus was $3.91 \mathrm{GPa}$.

\subsubsection{Experimental Model Similarity}

Considering the dimensions of converter station, marine hydrological parameters and laboratory conditions, the geometric scale of this test model was 1:60. The model similarity criterion is the key of this research, and the structural vibration should satisfy the elastic similarity as follows [19]:

$$
\lambda_{\rho} \cdot \lambda_{A} \cdot \lambda^{3} \cdot \lambda_{u} \cdot \lambda_{t}^{-2}=\lambda_{I} \cdot \lambda_{E} \cdot \lambda_{u} \cdot \lambda^{-3}
$$

where $\lambda_{\rho}$ is the density scale, $\lambda$ is the geometric scale, $\lambda_{u}$ is the deformation scale, $\lambda_{E}$ is the elastic modulus, $\lambda_{t}$ is the time scale, $\lambda_{A}$ is the sectional area scale and $\lambda_{I}$ is the sectional moment of the inertia scale.

For a structure dominated by bending vibration, the elastic similarity law can be rewritten as follows:

$$
\lambda_{t}^{2}=\lambda^{4} \cdot \lambda_{\rho} \cdot \lambda_{E}^{-1} \cdot \lambda_{r}^{-2}
$$

where $\lambda_{r}$ is the radius of the inertia scale.

Froude number is the ratio of inertial force to gravity. Thus, Froude number similarity represents the similarity relationship between the inertial force and gravity, which is expressed as follows [20]:

$$
\lambda_{v}=\lambda^{0.5}
$$

where $\lambda_{v}$ is the speed scale.

Considering acceleration scale is $\lambda_{g}=1$, thus,

$$
\lambda_{t}=\lambda^{0.5}
$$

Combining the Equations (2) and (4), and simultaneously satisfy elastic similarity and Froude number similarity, the hydroelastic similarity can be given as follow:

$$
\lambda^{3} \cdot \lambda_{r}^{-2}=\lambda_{E}
$$

The prototype structural material was steel, and its elastic modulus was 206 GPa. The model material was plexiglass, and its dynamic elastic modulus was $3.91 \mathrm{GPa}$. Therefore, the elastic modulus scale was 52.69. The ratio of the section radius of inertia was 64.027. The similarity relations of other parameters could be calculated according to the geometric scale and the sectional radius of the inertia scale. The similarity relations of basic parameters are summarized in Table 1. Some of the similarities relations related to the section took the platform leg as an example. 
Table 1. The similarity relation of basic parameters for the model design. Taking the platform leg as an example.

\begin{tabular}{ccc}
\hline Parameter & Similarity & Similar scale \\
\hline Length & $\lambda$ & 60 \\
Area & $\lambda_{A}$ & 1120.7 \\
Volume & $\lambda \cdot \lambda_{A}$ & 67241 \\
Density & $\lambda_{\rho}=1$ & 1 \\
Mass & $\lambda_{\rho} \cdot \lambda \cdot \lambda_{A}$ & 67241 \\
Speed & $\lambda^{0.5}$ & 7.746 \\
Acceleration & $\lambda_{g}=1$ & 1 \\
Time & $\lambda^{0.5}$ & 7.746 \\
Frequency & $\lambda^{-0.5}$ & 0.129 \\
Force & $\lambda^{3}$ & $60^{3}$ \\
Moment & $\lambda^{4}$ & $60^{4}$ \\
Moment of area & $\lambda_{A} \cdot \lambda_{r}{ }^{2}$ & $4.59 \times 10^{6}$ \\
Moment of mass & $\lambda \cdot \lambda_{A} \cdot \lambda_{r}{ }^{2}$ & $2.76 \times 10^{8}$ \\
Stress & $\lambda^{4} \cdot \lambda_{D} \cdot \lambda_{A}{ }^{-1} \cdot \lambda_{r}{ }^{-2}$ & 176.3 \\
\hline
\end{tabular}

\subsubsection{Geometric Dimension Design of the Experimental Model}

With reference to the prototype structure of the electrical platform, the geometric dimensions of each component of the test model were determined according to the geometric scale and the inertia radius scale. Schematic diagram of the electrical platform is shown in Figure 1. The parameters of the superstructure model are shown in Table 2. The lower jacket structure was mainly the cylindrical steel pipe. The length of the members and the outer diameter of the pile legs strictly followed the geometric scale; therefore, the hydrodynamic characteristics of the platform could be simulated accurately. The pipe section of the pile leg was calculated according to the area scale to achieve the accurate simulation of the elastic response of the structure (see Table 3).

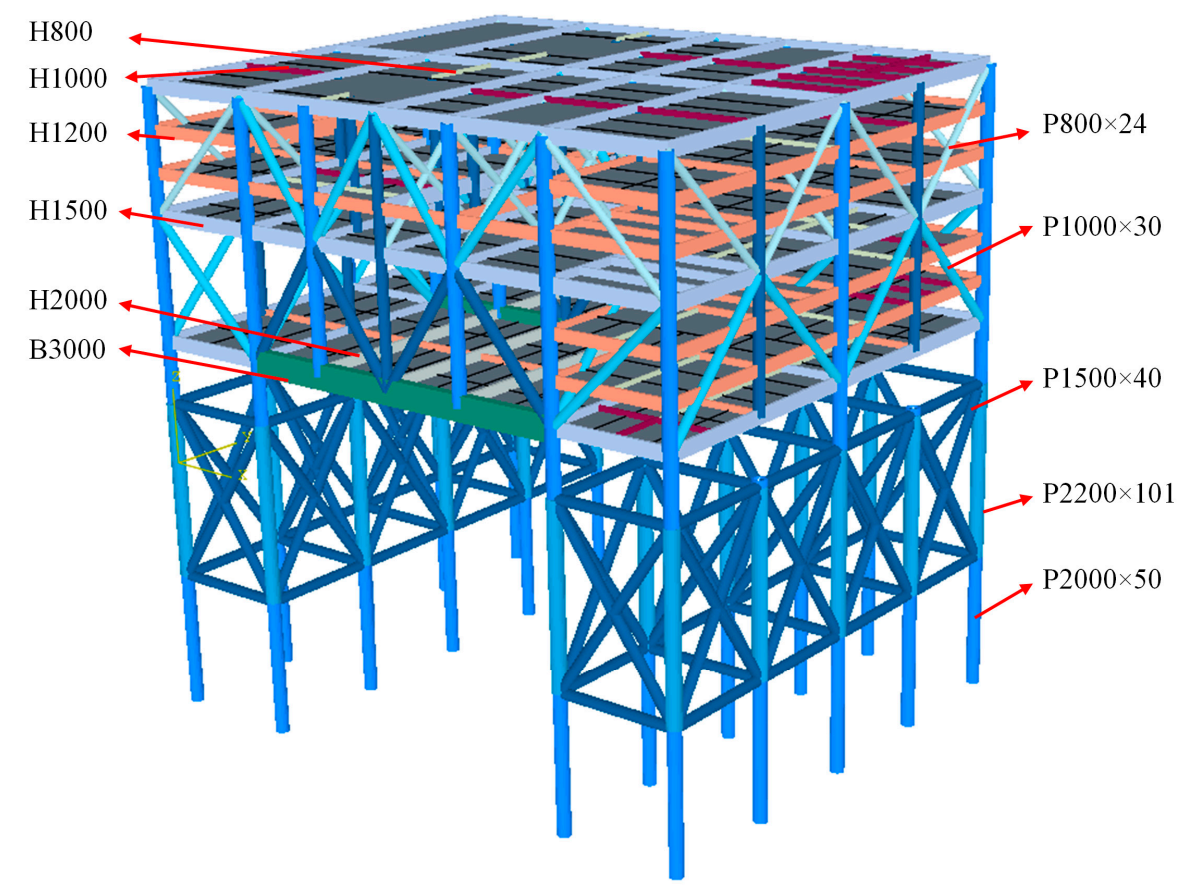

Figure 1. Schematic diagram of the electrical platform. 
Table 2. Geometric dimension parameters of the superstructure model.

\begin{tabular}{cccc}
\hline Member Type & Model Number & Sectional Dimension $\mathbf{( m m )}$ & Section for Model \\
\hline Box beam & B3000 & $59.1 \times 23$ & \\
& H2000 & $45.5 \times 8.6$ & Rectangular section \\
I-beam & H1500 & $34.2 \times 6.8$ & (Height $\times$ Width) \\
& H1000 & $27.6 \times 6.4$ & \\
& H 800 & $22.8 \times 5.1$ & Pipe (Outside diameter $\times$ \\
Pipe & P1500 $0050 \times 40$ & $32 \times 3$ & Thickness) \\
& P1000 $\times 30$ & $25 \times 2$ & Solid bar (Diameter) \\
\hline
\end{tabular}

Table 3. Geometric dimension parameters of the jacket structure model.

\begin{tabular}{cccc}
\hline Member Type & Model Number & Sectional Dimension $\mathbf{( m m )}$ & Section for Model \\
\hline \multirow{2}{*}{ Pipe } & $\mathrm{P} 2200 \times 101$ & $35 \times 5$ & Pipe (Outside diameter $\times$ \\
& $\mathrm{P} 2000 \times 50$ & $32 \times 3$ & Thickness) \\
\hline
\end{tabular}

\subsubsection{Counterweight Design of the Experimental Model}

Due to the difference of the prototype and model material, the weight distribution on the platform was different. Therefore, the sheet lead was used to balance each component of the model structure in this study. For the structural mass of the model component, the weight was scaled according to the mass scale. For the non-structural mass, such as the weight of the equipment, it was scaled as force. Thus, both gravity similarity and hydroelastic similarity were satisfied. Finally, the balance weight was $274.4 \mathrm{~kg}$ for the superstructure and $76.9 \mathrm{~kg}$ for the jacket model. The total weight of the platform model was $427.8 \mathrm{~kg}$.

\subsubsection{Equivalent Pile Design of the Experimental Model}

The foundation of the electrical platform was the pile foundation. However, in the laboratory test, the soil data was difficult to determine. Coupled with the complexity of the seismic load, it was difficult to directly simulate the interaction between the pile and soil. Therefore, it was necessary to adopt a simplified approach instead. In this study, the equivalent pile method was used to simulate the pile-soil interaction of the converter station [21]. Firstly, the finite element model was established to simulate the nonlinear characteristics between pile and soil based on the p-y method. Then, taking the structural basic frequency as the constraint condition, the relationship between the equivalent pile length and pile diameter was determined by adjusting the equivalent pile length. In this study, the equivalent pile length of the electrical platform model was determined to be seven times the pile diameter. In the experiment, the 20 piles of the platform were fixed at the vibration table through two plexiglass plates.

\subsection{Laboratory Setup}

The laboratory experiments were conducted in a wave and current flume at the State Key Laboratory of Coastal and Offshore Engineering (SLCOE), Dalian University of Technology, Dalian, China. The flume was $21.6 \mathrm{~m}$ long, $5.0 \mathrm{~m}$ wide and $1.0 \mathrm{~m}$ deep. The flume was equipped with an elliptic underwater vibration table (see Figure 2) and earthquake simulating system. Basic parameters of the earthquake simulating system are shown in Table 4.

Based on the consideration of the structural symmetry, the laboratory experiment of the electrical platform using an underwater earthquake simulating system was carried out under the typical seismic 
propagation direction, where the normal direction was determined to be the most dangerous direction. The experimental arrangement is shown in Figure 3.

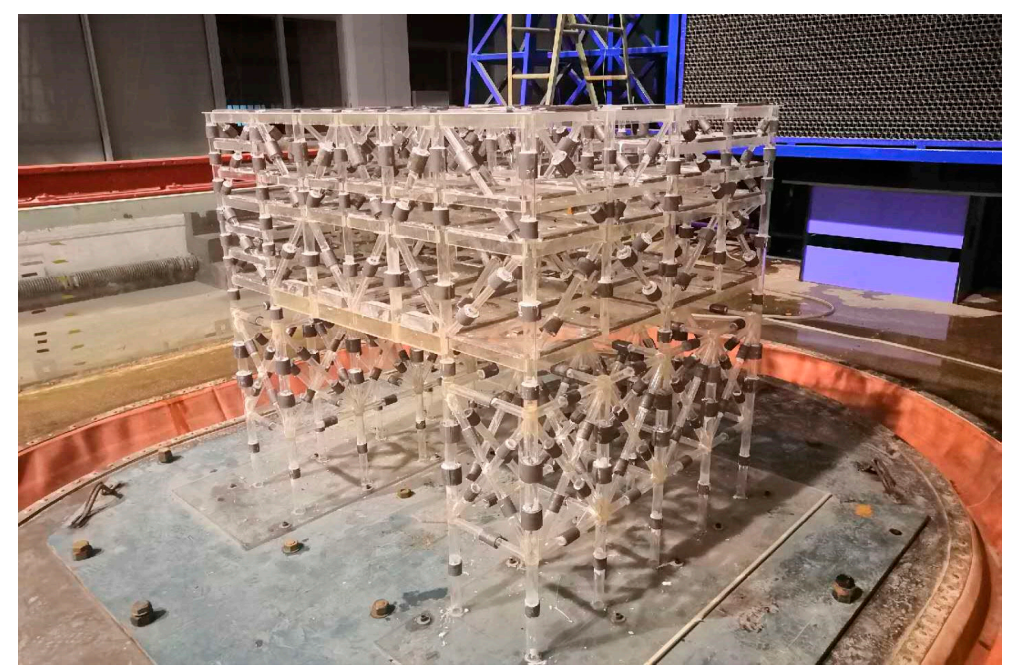

Figure 2. The elliptic underwater vibration table in the flume.

Table 4. Parameters of the earthquake simulating system.

\begin{tabular}{cc}
\hline Parameter & Value \\
\hline Sizes of Shaking Table & $4 \mathrm{~m} \times 3 \mathrm{~m}$ \\
Max. Loading Mass & $10,000 \mathrm{~kg}$ \\
Max. Horizontal Displacement & $\pm 75 \mathrm{~mm}$ \\
Max. Horizontal Velocity & $50 \mathrm{~cm} / \mathrm{s}$ \\
Max. Horizontal Acceleration & $1.0 \mathrm{~g}$ \\
Max. Vertical Displacement & $\pm 50 \mathrm{~mm}$ \\
Max. Vertical Velocity & $35 \mathrm{~cm} / \mathrm{s}$ \\
Max. Vertical Acceleration & $0.7 \mathrm{~g}$ \\
Operation Frequency Range & $0-50 \mathrm{~Hz}$ \\
\hline
\end{tabular}

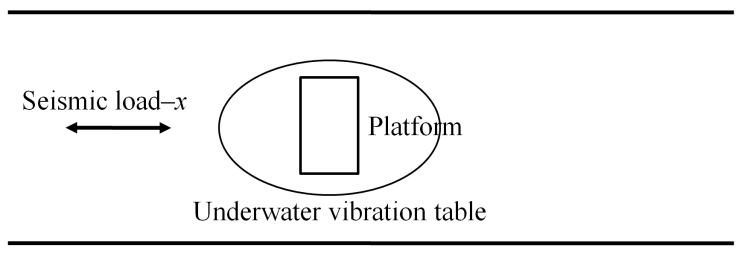

(a)

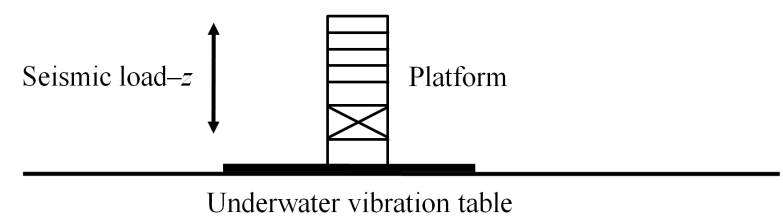

(b)

Figure 3. The experimental layout of the electrical platform model. (a) Top view and (b) side view.

In this experiment, strain data at some key positions of the platform structure was collected using some strain gauges (Figure 4) and a data acquisition instrument from the National Instrument (Figure 5). Waterproof and non-waterproof acceleration sensors (Figure 6) were adopted to measure the acceleration response at key positions on the platform structure and equipment. The measuring range of the acceleration sensor was $1.0 \mathrm{~g}$, the accuracy was up to $0.3 \%$ and the measuring frequency was up to $1000 \mathrm{~Hz}$. The displacement response of the structure was measured by the laser displacement meter, as shown in Figure 7. 

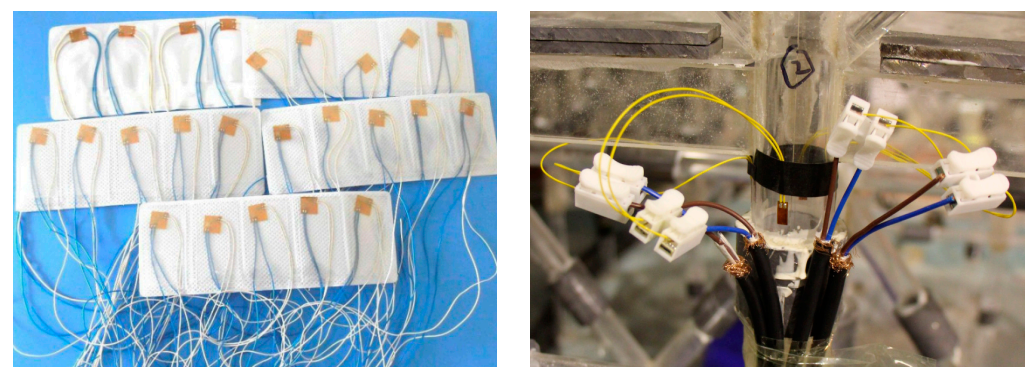

Figure 4. The experimental layout of the strain gauge.

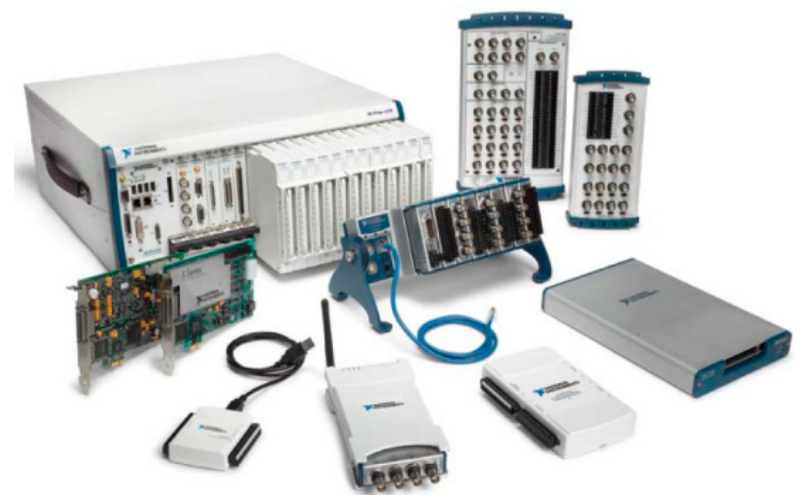

Figure 5. The National Instruments (NI) data acquisition instrument used in this experiment.
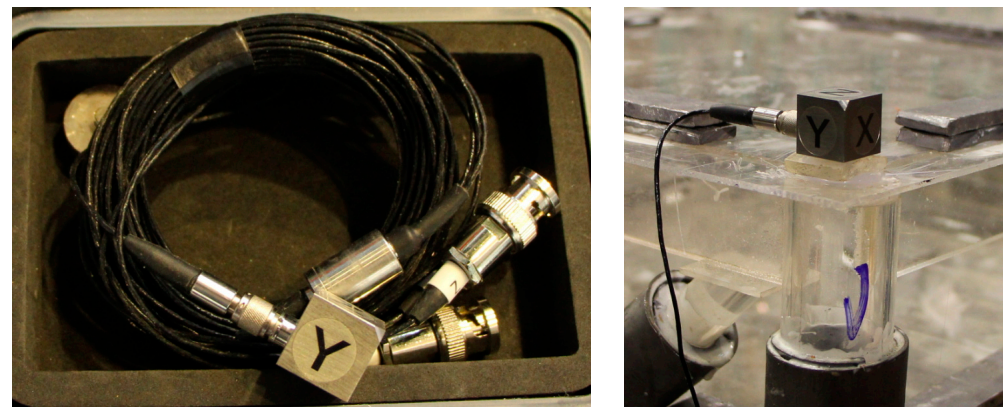

Figure 6. The experimental layout of the acceleration sensor.
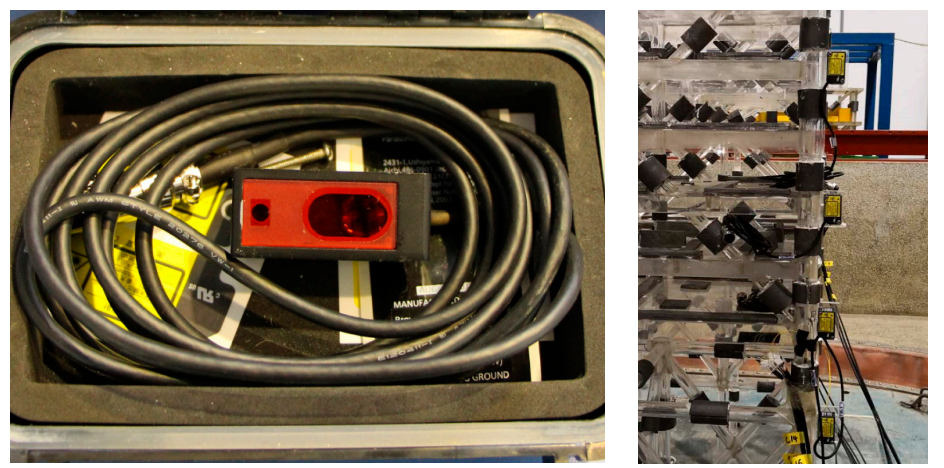

Figure 7. The experimental layout of the laser displacement meter.

\subsection{Experimental Conditions}

The water depth was $0.32 \mathrm{~m}$ during this experiment, and the corresponding prototype water depth was $19.4 \mathrm{~m}$ with the model scale of 1:60. There were no water waves and only the seismic load was applied during experiments. The dynamic response of the electrical platform structure excited by different seismic waves would be tested to obtain the time history curve of the dynamic response 
of the jacket electrical platform structure. The seismic loads in this experiment, presented in Table 5, included four recorded earthquake waves from the ground motion database of the Pacific Earthquake Engineering Research Center (PEER) and one artificial earthquake wave based on the spectrum of the API standard [21]. The four selected seismic spectrums were compared with the standard spectrum, and the overall error was within $20 \%$.

Table 5. The seismic loads in the experiment.

\begin{tabular}{|c|c|c|}
\hline Seismic Wave & Excitation Orientation & Water Level \\
\hline API & & \\
\hline $\begin{array}{c}\text { RSN169_IMVPALL } \\
\text { RSN800_LOMAP }\end{array}$ & $x$ & Without level \\
\hline $\begin{array}{c}\text { RSN1116_KOBE } \\
\text { RSN6988_DARFIELD }\end{array}$ & $\mathrm{z}$ & Mean water level \\
\hline
\end{tabular}

In order to eliminate the residual strain in the model, a sufficient time interval was set between two adjacent tests. To study the influence of water damping effect on the dynamic response of the platform structure, the dynamic response characteristics of the electrical platform under seismic load were tested with and without water respectively. The excitation direction of seismic wave could be divided into two working conditions: Unidirectional ( $x$ direction) and bidirectional ( $x$ and $z$ direction). The ratio of the peak acceleration was $x: z=1: 0.5$ for the bidirectional seismic excitation.

\subsection{Measuring-Point Arrangement}

To measure the structural strain, seven key nodes were selected on the electrical platform and four strain gauges were arranged in an orthogonal form for each node. Eleven acceleration sensors were used, including nine on the electrical platform and two on the ground for reference. Along a pile leg, five displacement sensors were arranged from top to bottom to measure the displacement response of the structure under the earthquake load (Figure 8).

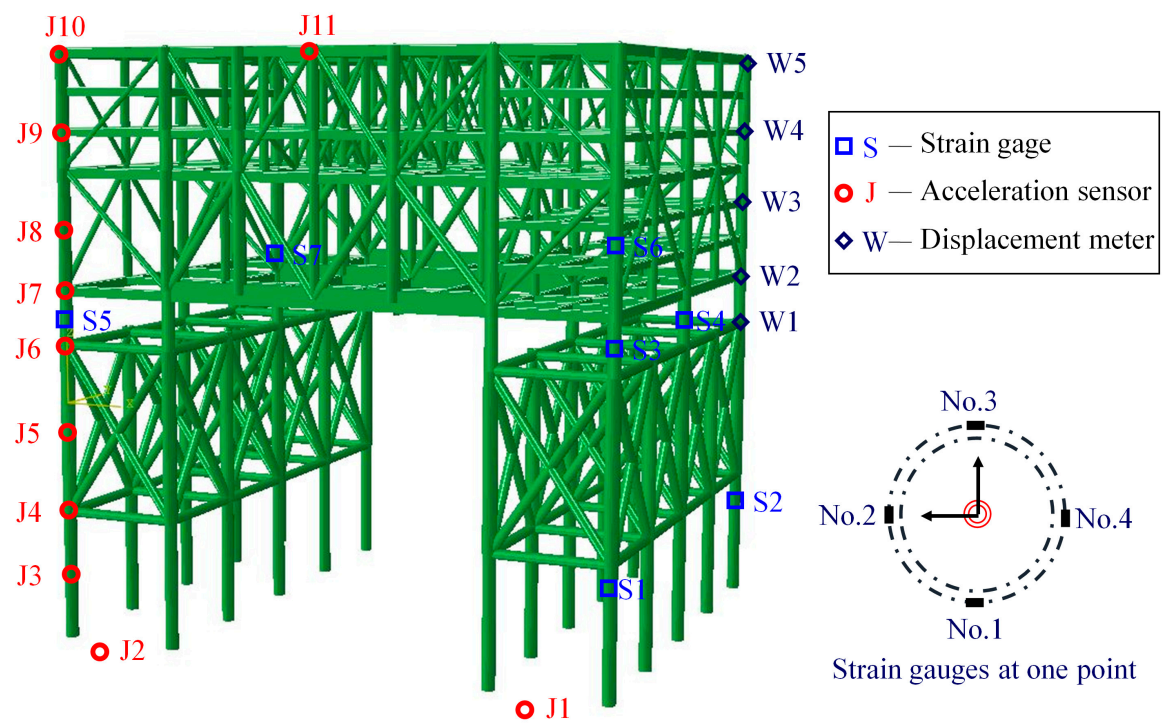

Figure 8. Measurement position of the earthquake response at key nodes of the electrical platform.

\subsection{Experimental Uncertainties}

The physical model of the electrical platform was made of plexiglass pipes and plates. Although the model size was carefully designed, there would inevitably be global and local dimension errors when manufacturing the experimental model. An uncertainty of $\pm 1 \%$ in the dimensions of model height, width and pipe diameter might seem realistic. 
The tested seismic wave was converted from the time series of the measured seismic wave. However, the time series of the output seismic wave acceleration still had some biases. Therefore, dimensionless results were analyzed and discussed in this study.

There will be some random error in the experiment. Due to various accidental factors, such as the measurement accuracy of the instrument, the measurement value might deviate from the true value. In this experiment, the same physical quantity was measured for several times to get the average value, so as to reduce accidental errors.

\section{Results}

\subsection{Basic Dynamic Parameters of the Electrical Platform}

In this section, an experimental study on the dynamic characteristics of the offshore electrical platform was conducted. By white noise excitation, the structural dynamic parameters such as structural frequency, mode of vibration and damping ratio were obtained.

\subsubsection{Structural Frequency}

According to the time-series data of the structural acceleration response collected by the acceleration sensor, the corresponding power spectral density of each point was calculated. Taking measurement point J4 for acceleration as an example, the time-series of acceleration response and power spectral density function at the pile leg with and without water are shown in Figure 9. The frequency corresponding to the first peak of the power spectral density function was the fundamental frequency in the normal $(x)$ direction of the model structure. The frequency corresponding to the first peak of the power spectral density function was the fundamental frequency in the $x$-direction of the model structure.
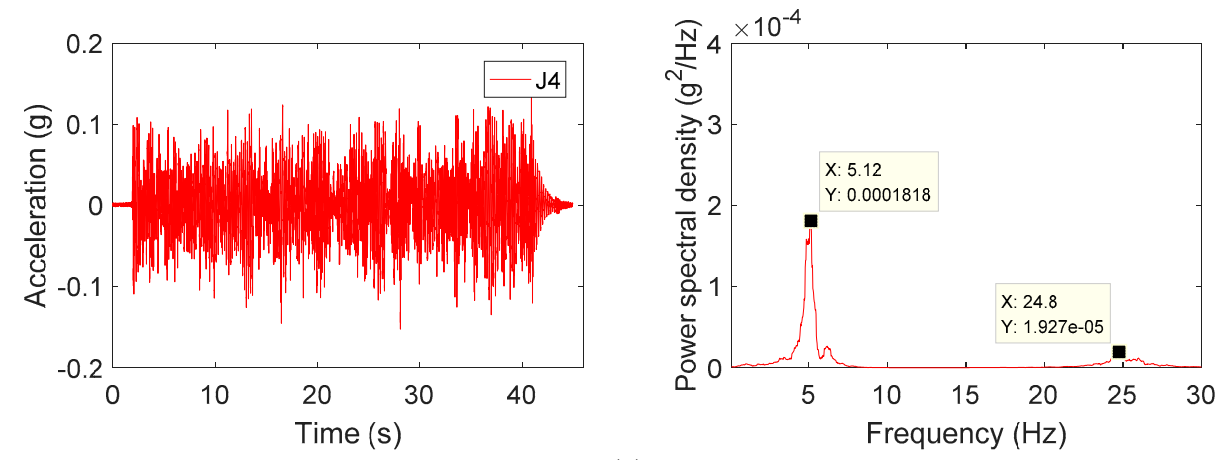

(a)
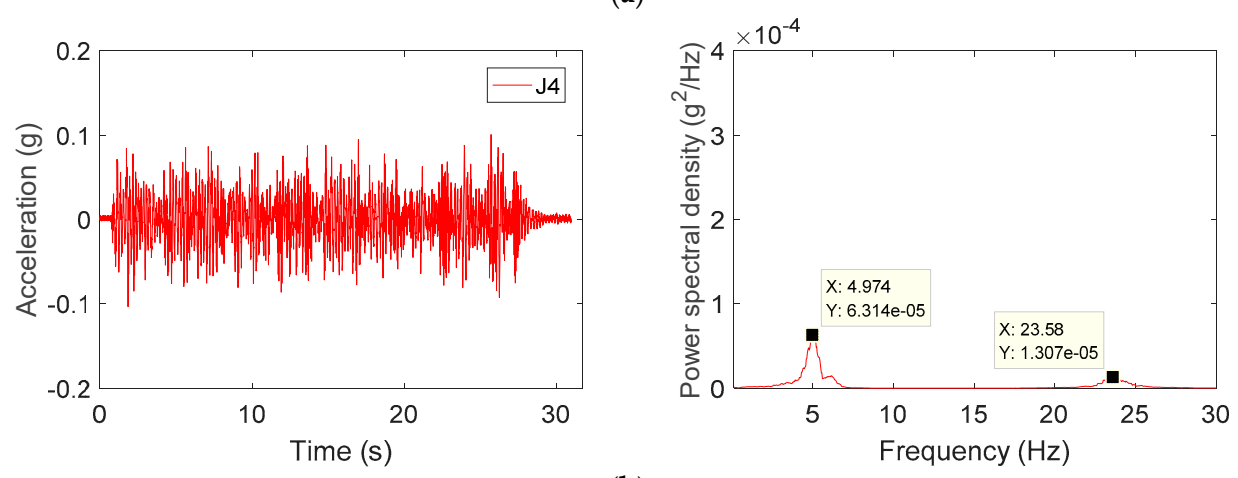

(b)

Figure 9. Time-series of the acceleration response and power spectral density function. (a) Without water and (b) with water.

The first-order mode frequencies of the electrical platform along the normal direction with and without water conditions were $5.12 \mathrm{~Hz}$ and $4.974 \mathrm{~Hz}$, respectively. The results showed that the 
fundamental frequency of the structure with water was lower than that without water due to the water induced additional mass of the structure.

\subsubsection{Mode of Vibration}

The vibration modes of the electrical platform in with/without water states were analyzed under the excitation of white noise. The power spectral density function of acceleration response data of each measurement point was calculated. The structural mode of vibration is shown in Tables 6 and 7 for the electrical platform in with/without water states, respectively. The mode shape of the structure is shown in Figure 10. The mode showed a relatively high consistency between the presence and absence of water.

Table 6. Power spectrum peaks of the first and second mode in the without water condition.

\begin{tabular}{|c|c|c|c|c|c|}
\hline \multirow{2}{*}{$\begin{array}{l}\text { Measuring } \\
\text { Point }\end{array}$} & \multirow{2}{*}{ Height (m) } & \multicolumn{2}{|c|}{ Amplitude of First Mode } & \multicolumn{2}{|c|}{ Amplitude of Second Mode } \\
\hline & & $\begin{array}{l}\text { Original Value } \\
\qquad\left(10^{-4}\right)\end{array}$ & $\begin{array}{l}\text { Normalized } \\
\text { Value }\end{array}$ & $\begin{array}{l}\text { Original Value } \\
\qquad\left(10^{-7}\right)\end{array}$ & $\begin{array}{c}\text { Normalized } \\
\text { Value }\end{array}$ \\
\hline $\mathrm{J} 2$ & 0 & 0.000 & 0.000 & 0.000 & 0.000 \\
\hline $\mathrm{J} 3$ & 0.22 & 0.882 & 0.286 & -76.950 & -0.339 \\
\hline $\mathrm{J} 4$ & 0.415 & 1.828 & 0.593 & -191.400 & -0.844 \\
\hline J5 & 0.56 & 1.800 & 0.583 & -226.900 & -1.000 \\
\hline J6 & 0.76 & 2.054 & 0.666 & -87.250 & -0.385 \\
\hline J7 & 0.92 & 2.523 & 0.818 & 0.259 & 0.001 \\
\hline J8 & 1.12 & 3.064 & 0.993 & 8.173 & 0.036 \\
\hline J9 & 1.306 & 3.079 & 0.998 & 13.470 & 0.059 \\
\hline J10 & 1.53 & 3.085 & 1.000 & 24.640 & 0.109 \\
\hline
\end{tabular}

Table 7. Power spectrum peaks of the first and second mode in water condition.

\begin{tabular}{|c|c|c|c|c|c|}
\hline \multirow{2}{*}{$\begin{array}{l}\text { Measuring } \\
\text { Point }\end{array}$} & \multirow{2}{*}{ Height (m) } & \multicolumn{2}{|c|}{ Amplitude of First Mode } & \multicolumn{2}{|c|}{ Amplitude of Second Mode } \\
\hline & & $\begin{array}{l}\text { Original Value } \\
\qquad\left(10^{-4}\right)\end{array}$ & $\begin{array}{l}\text { Normalized } \\
\text { Value }\end{array}$ & $\begin{array}{l}\text { Original Value } \\
\qquad\left(10^{-7}\right)\end{array}$ & $\begin{array}{c}\text { Normalized } \\
\text { Value }\end{array}$ \\
\hline $\mathrm{J} 2$ & 0 & 0.000 & 0.000 & 0.000 & 0.000 \\
\hline $\mathrm{J} 3$ & 0.22 & 0.307 & 0.295 & -55.990 & -0.364 \\
\hline $\mathrm{J} 4$ & 0.415 & 0.631 & 0.608 & -131.600 & -0.856 \\
\hline J5 & 0.56 & 0.619 & 0.596 & -153.800 & -1.000 \\
\hline J6 & 0.76 & 0.686 & 0.660 & -57.870 & -0.376 \\
\hline $\mathrm{J} 7$ & 0.92 & 0.846 & 0.814 & 0.630 & 0.004 \\
\hline J8 & 1.12 & 1.000 & 0.962 & 7.823 & 0.051 \\
\hline J9 & 1.306 & 1.038 & 0.999 & 11.470 & 0.075 \\
\hline $\mathrm{J} 10$ & 1.53 & 1.039 & 1.000 & 17.250 & 0.112 \\
\hline
\end{tabular}

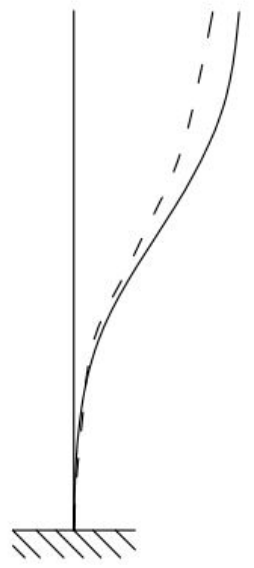

(a)

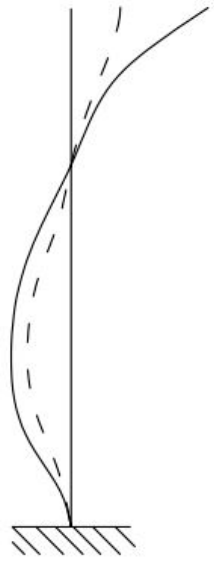

(b)

Figure 10. Structural mode of vibration. The solid line presents the results without water and the dotted line presents the results with water. (a) First-order mode of vibration and (b) second-order mode of vibration. 


\subsubsection{Damping Ratio}

Taking acceleration data at J10 on the top of the platform as an example, the power spectral density functions are shown in Figure 11. For without water state, frequency peak of the first-order vibration mode of the power spectral density function was $3.058 \times 10^{-4} \mathrm{~g}^{2} / \mathrm{Hz}$. The half peak was $1.529 \times 10^{-4} \mathrm{~g}^{2} / \mathrm{Hz}$. The corresponding frequencies could be obtained from Figure $11 \mathrm{a}$ as $f_{1}=4.767$ and $f_{2}=5.347$, respectively. Thus, the damping ratio could be defined as follows:

$$
\zeta=\frac{f_{2}-f_{1}}{f_{2}+f_{1}}=\frac{5.347-4.767}{5.347+4.767}=5.73 \%
$$

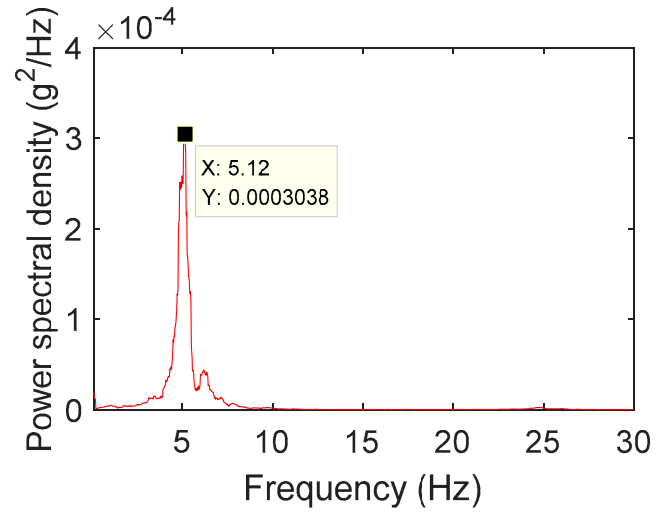

(a)

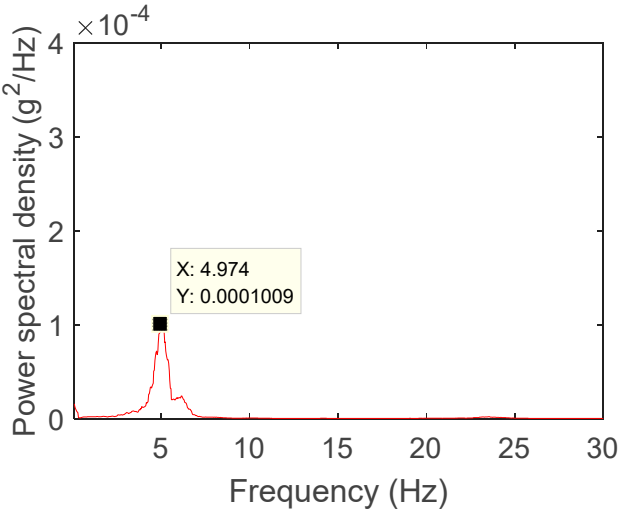

(b)

Figure 11. Power spectral density function of acceleration sensor J10. (a) Without water and (b) with water.

While, the damping ratio of the vibration mode was $8.68 \%$ for the with water state. The results for different measurement positions are present in Table 8. According to the experimental results, the average damping ratio of the first-order mode in the $x$-direction was $5.46 \%$ in the without water state, while it was $8.42 \%$ in the with water state. The damping ratio of the platform in water was larger than that without water. It was determined that the structural damping would increase due to the existence of water damping when the wind farm electrical platform was exposed in the open sea.

Table 8. Damping ratio of the first-order mode of the platform.

\begin{tabular}{|c|c|c|c|c|c|c|c|c|c|c|}
\hline $\begin{array}{l}\text { Measuring } \\
\text { Point }\end{array}$ & J3 & $\mathrm{J} 4$ & J5 & J6 & $\mathrm{J} 7$ & $\mathrm{~J} 8$ & J9 & $\mathrm{J} 10$ & J11 & $\begin{array}{l}\text { Mean } \\
\text { Value }\end{array}$ \\
\hline Without water & $5.32 \%$ & $5.35 \%$ & $5.26 \%$ & $5.65 \%$ & $5.52 \%$ & $5.36 \%$ & $5.63 \%$ & $5.73 \%$ & $5.34 \%$ & $5.46 \%$ \\
\hline With water & $7.83 \%$ & $8.67 \%$ & $8.25 \%$ & $8.52 \%$ & $8.66 \%$ & $8.72 \%$ & $8.66 \%$ & $8.68 \%$ & $7.82 \%$ & $8.42 \%$ \\
\hline
\end{tabular}

\subsection{Strain Response of the Electrical Platform}

The time series of the strain response on the pile leg of the electrical platform showed a good following feature with the seismic excitation (see Figure 12). The strain at the normal positions of the pile leg was obviously larger than that at the tangential position on two sides. According to the strain analysis, the ratio of the four strain gauges at the same position in various test conditions remained basically unchanged. The strain ratios of the four strain gauges at measuring point $\mathrm{S} 1$ were averaged among different seismic excitations and the strain-peak ratios of strain gauges no. 1 to no. 4 were 0.745:0.177:1:0.215. The strain-peak ratios for measuring points S2, S3 and S4 were 1:0.428:0.747:0.153, 0.548:0.378:1:0.429 and 0.897:0.257:1:0.226, respectively. 


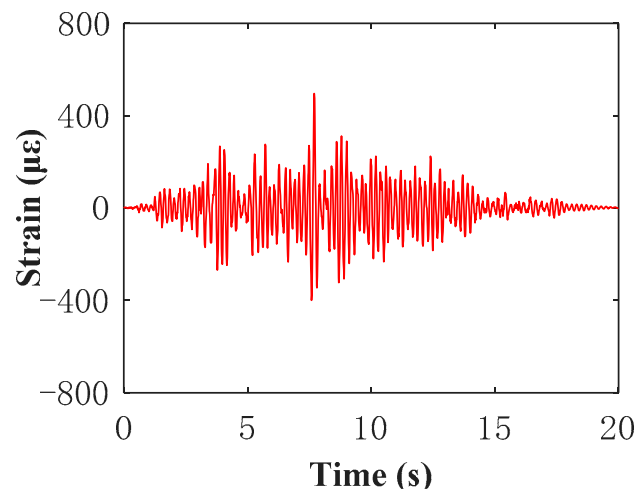

(a)

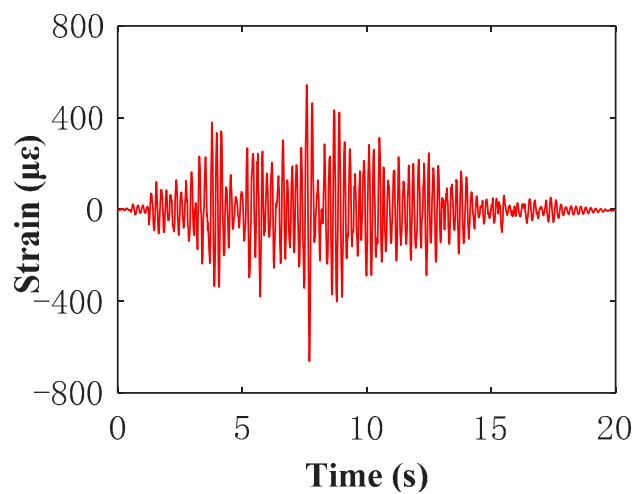

(c)

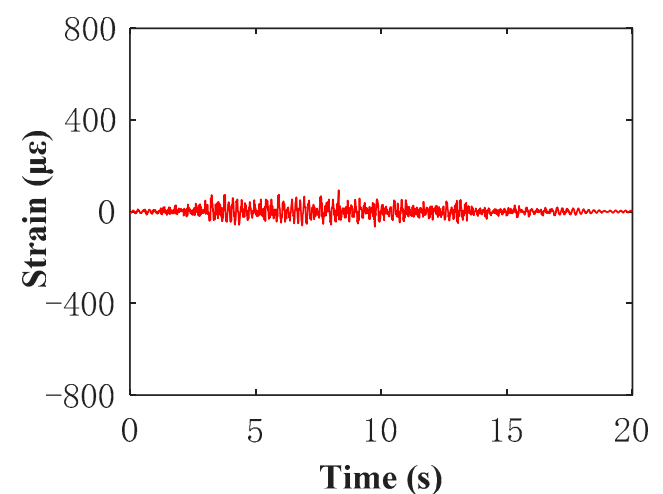

(b)

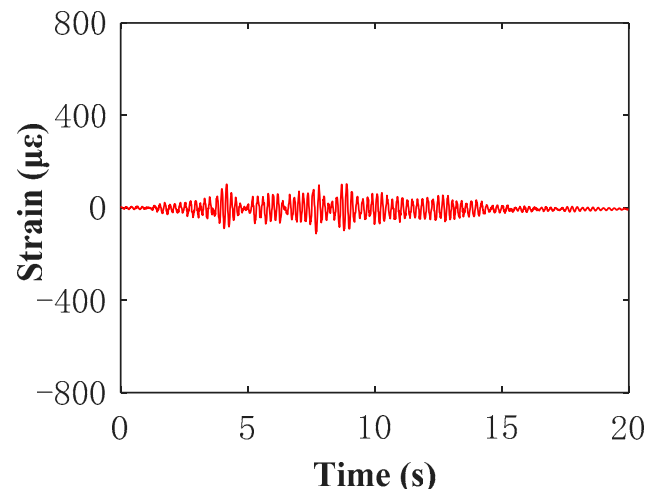

(d)

Figure 12. Time series of the strain response on measuring point S1. API (American Petroleum Institute) seismic wave with a peak ground acceleration of $0.25 \mathrm{~g}$. (a) Strain at strain gauge no. 1 , (b) strain at strain gauge no. 2, (c) strain at strain gauge no. 3 and (d) strain at strain gauge no. 4.

The structural strain increased with the increase of seismic excitation intensity (see Figure 13). When the peak acceleration of the input seismic wave was within the range of $0.2 \mathrm{~g}$, the relationship between the structural strain response and the seismic acceleration was approximately linear. As the input acceleration of the foundation increased, the peak strain response of the structure changed nonlinearly due to the nonlinear interaction between water and structure.

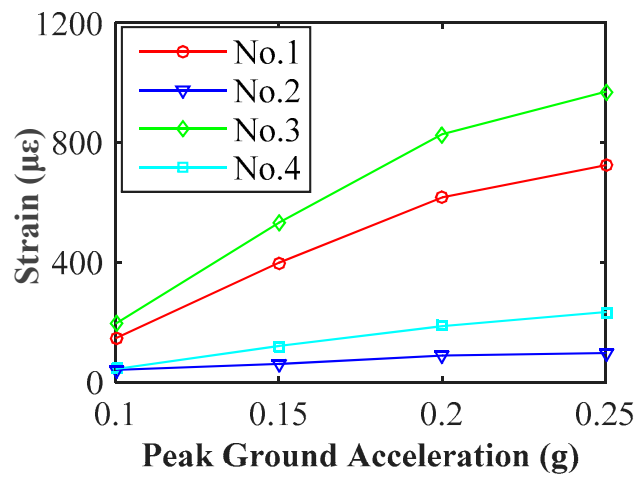

(a)

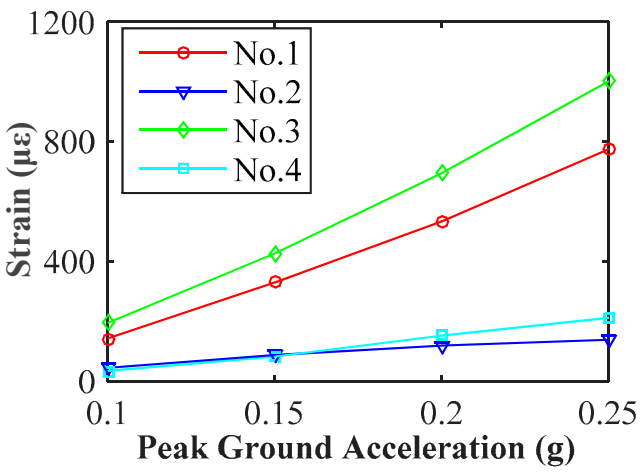

(b)

Figure 13. The peak value of the strain response on measuring point $\mathrm{S} 1$ for various seismic accelerations. (a) RSN169_IMVPALL and (b) RSN1116_KOBE.

According to the relationship between the stress and strain of the plexiglass material, the stress of the structure can be calculated according to the results of the strain. Combined with the stress similarity relation of model structure and prototype structure, the stress similarity scale of this model test was 
determined to be 176.31. Thus the stress of the structural model could be converted to that of the prototype structure. For the electrical platform, the structural strength of the upper structure and the upper and lower joint parts needed more attention. According to the test results, the maximum stress value at measuring points S3, S4, S5 and S6 reaches $115.8 \mathrm{MPa}, 223.1 \mathrm{MPa}, 137.4 \mathrm{MPa}$ and $22.1 \mathrm{MPa}$, respectively, when the peak acceleration was $0.25 \mathrm{~g}$. The results show that the maximum stress value on the prototype electrical platform structure was $223.1 \mathrm{MPa}$.

\subsection{Motion Response of the Electrical Platform}

The peak acceleration response of the structure was the maximum acceleration response of the structure under the action of corresponding seismic wave, which is an important index to reflect the seismic response of the structure. Overall, the acceleration response peak at different positions of the structure increased with increasing input seismic excitation. Due to the damping effect of water on the structure, the peak acceleration response of the structure varied nonlinearly with the input acceleration. The peak value of the acceleration responses for various seismic accelerations of the artificial and observed seismic wave is presented in Figure 14.

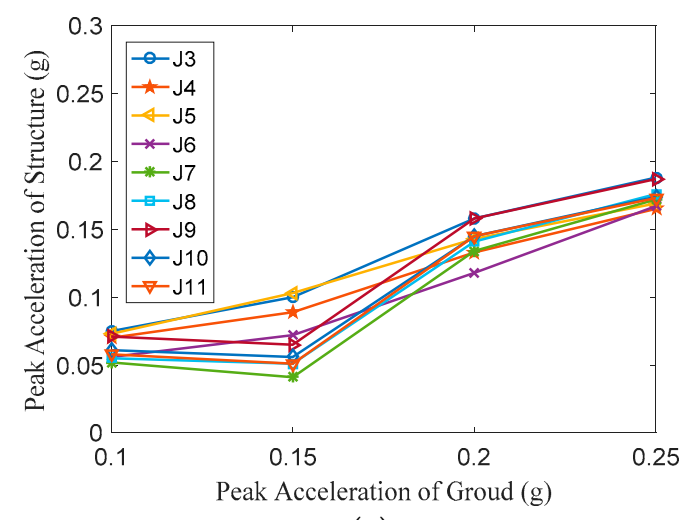

(a)

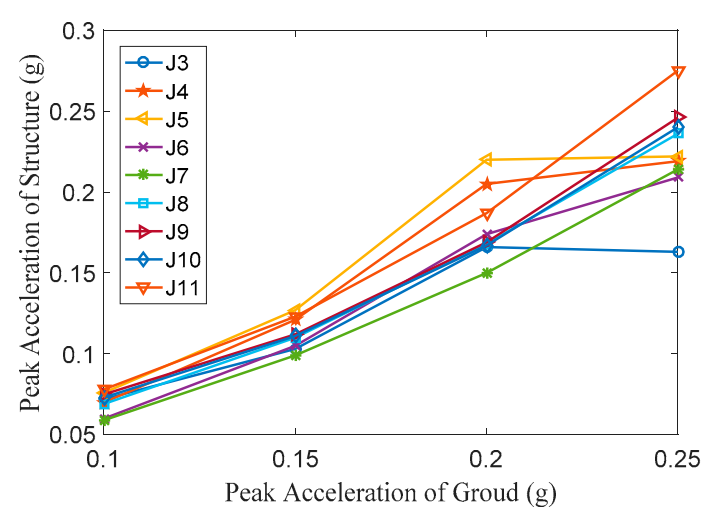

(b)

Figure 14. The peak value of the acceleration response for various seismic accelerations. (a) API and (b) RSN169_IMVPALL.

Under the action of different seismic waves, the peak accelerations at different positions on the structure were mainly concentrated around $5 \mathrm{~Hz}$ and $25 \mathrm{~Hz}$, which was the 1st- and 2nd-order mode frequencies in the x-direction of the structure (see Figure 15). By comparing the acceleration response results in the frequency domain of the acceleration sensors arranged along the pile leg, it could be seen that the peak value of the acceleration frequency domain results of the jacket structure at the bottom of the platform not only appeared near the frequency of the first vibration mode of the structure, but also produced obvious high-frequency components. For the acceleration sensors arranged on the superstructure of the platform, the peak value of acceleration in the frequency domain was mainly concentrated near the 1st-order mode frequency of the structure. The low-frequency component excited was relatively obvious. The frequency of acceleration transited from high frequency to low frequency along the height direction.

The displacement response of the structure in the horizontal direction was measured by the laser displacement sensor. The time-history curve of displacement response arranged at the five measuring points of the jacket and the superstructure of the platform is shown in Figure 16. The results show that the electrical platform would produce a significant displacement response under the excitation of seismic load. For different positions of the structure, the response trends were consistent. Overall, the displacement response amplitude of the platform structure was larger than the input value of the vibration table. It was indicated that the displacement response amplitude of the electrical platform had a certain dynamic amplification effect under the excitation of a seismic load. In this paper, the peak displacement response of the platform structure under five different seismic waves was analyzed. The 
results show that the peak displacement response of the platform under the action of seismic wave RSN800_LOMAP was the largest. The maximum displacement response was found at the top of the platform with $5.17 \mathrm{~mm}$, corresponding to the prototype value of $0.31 \mathrm{~m}$.

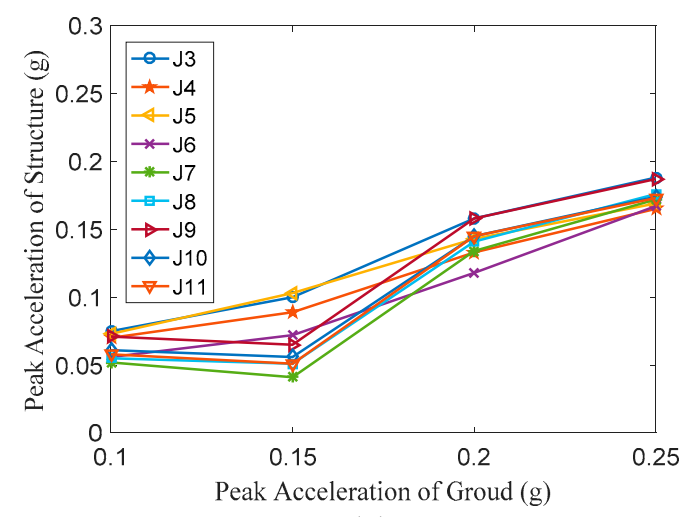

(a)

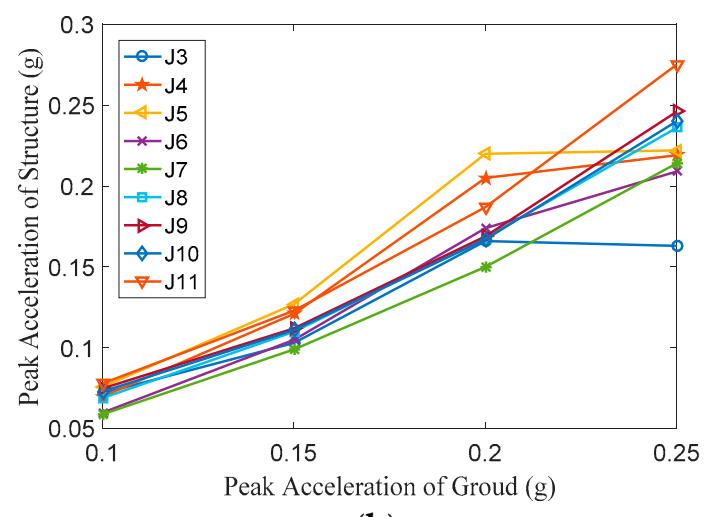

(b)

Figure 15. The peak value of the acceleration response for various seismic accelerations. (a) API and (b) RSN169_IMVPALL.

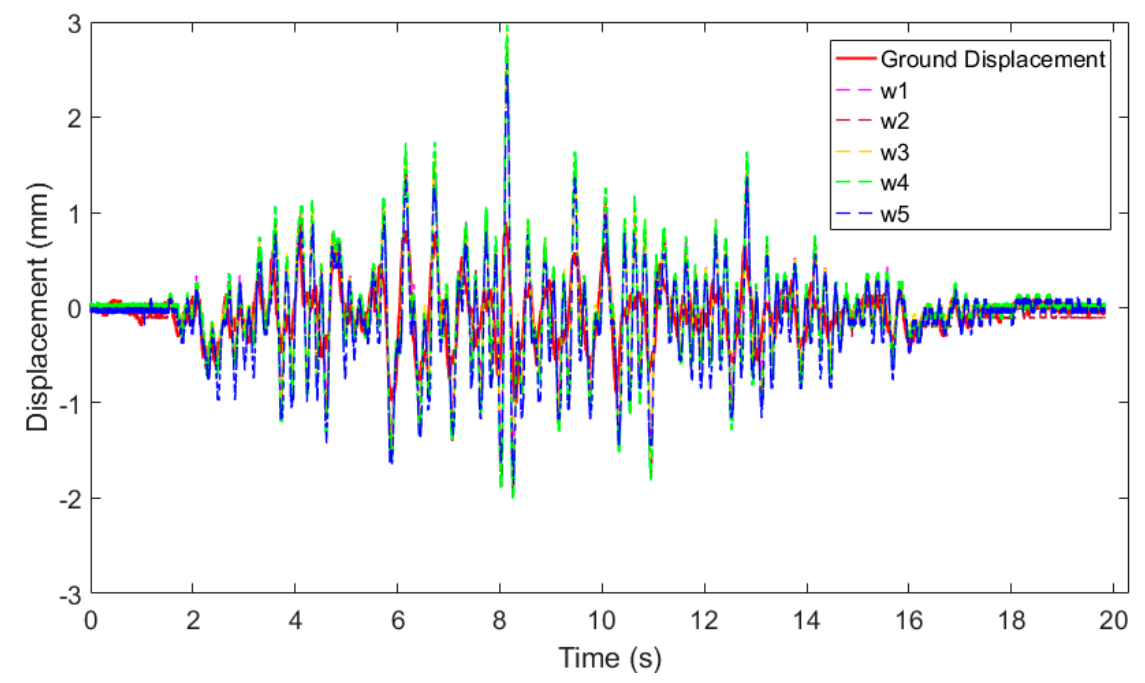

Figure 16. Time series of displacement response under the API seismic wave with a peak ground acceleration of $0.25 \mathrm{~g}$.

\section{Discussion}

\subsection{The Effect of Water Damping}

The experimental results show that the damping of the structure under the normal water level condition was larger than that without water. In general, the peak value of strain of the structure in with water state was smaller than that without water. This was consistent with that of the platform structure that experienced larger damping ratio under the normal water level condition. It was indicated that the strain response of the structure under the action of earthquake was suppressed due to the influence of water damping. Under the action of different seismic waves, the structural strain response of the electrical platform showed the same variation of the strain peak. Therefore, only the results under the action of API seismic wave are present here (see Figure 17). 


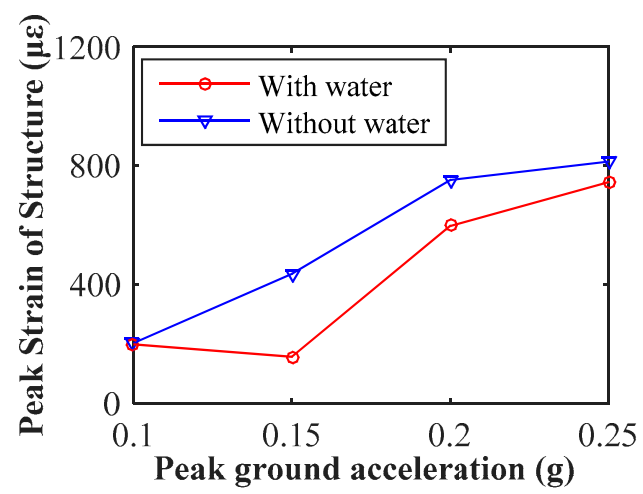

(a)

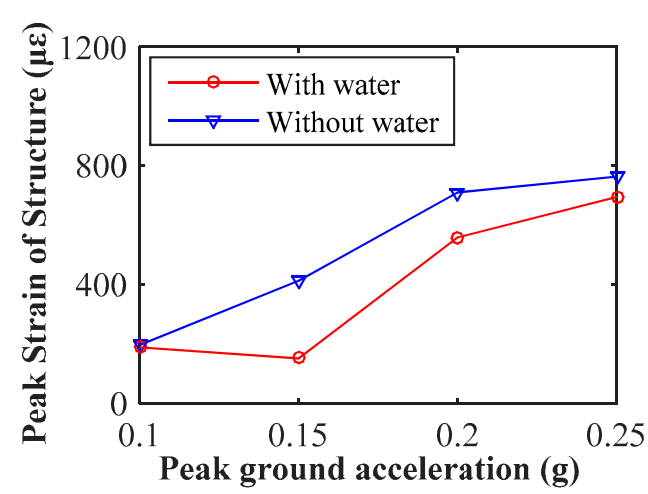

(b)

Figure 17. Structural strain response of the electrical platform in the with/without water condition under API seismic wave. (a) The strain response of S1 and (b) the strain response of S2.

Water damping had a significant influence on the acceleration response of the platform structure (see Figure 18). It could be seen from the distribution of structural peak acceleration at the representative positions that the peak acceleration of the structure under the condition of no water was greater than that with water. This was mainly due to the damping effect of water. It was indicated that the existence of water was beneficial to the stability of the structure under the action of an earthquake.

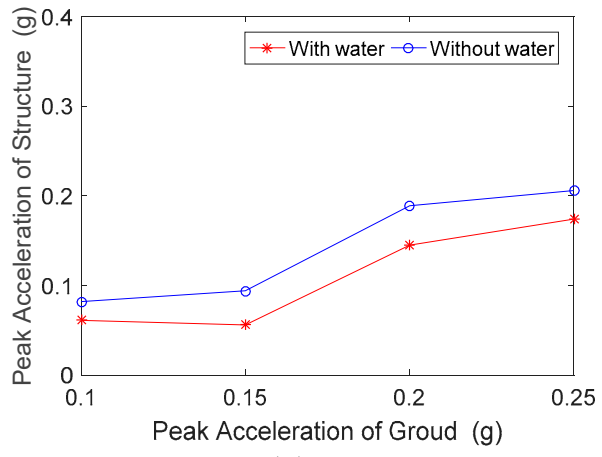

(a)

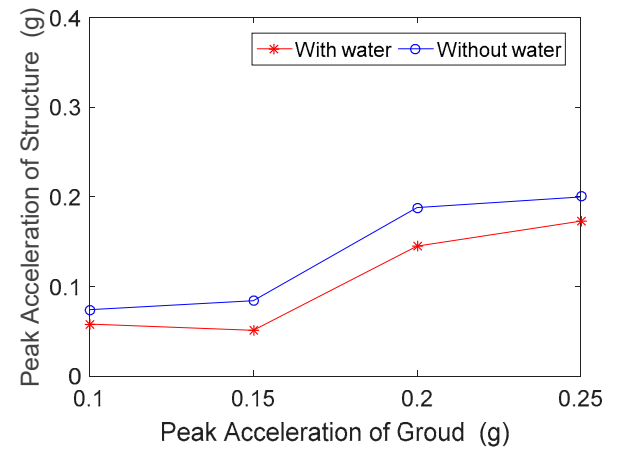

(b)

Figure 18. Structural peak acceleration of the electrical platform in the with/without water condition under the API seismic wave. (a) The acceleration response of J10 and (b) the acceleration response of J11.

\subsection{The Effect of the Seismic Loading Mode}

Taking the RSN1116_KOBE wave as an example, the dynamic response of the electrical platform under a unidirectional and bidirectional earthquake was compared (see Figure 19). With the increase of input peak acceleration, the strain response of the structure under unidirectional and bidirectional seismic action increased. In addition, the strain response peak value was approximately $35 \%$ larger on average in the case of bidirectional earthquake than that of a unidirectional earthquake. It can be considered that the bidirectional seismic load will cause stronger structural strain response, which is more harmful to the safety of the structure.

In the case of with and without water, the peak acceleration at different positions of the platform structure is shown in Figure 20. Under the action of the bidirectional seismic load, the acceleration response of the structure was greater than that under the unidirectional load. With the presence of water, the maximum increase of acceleration response of the structure, $\sim 23.66 \%$, occurred at measuring point J7. While in the dry mode, the maximum increase of the acceleration response of the structure, $\sim 23.46 \%$, occurred at measuring point J8. For both the with and without water conditions, the average increment of the acceleration response of the structure under a bidirectional seismic load was $18.86 \%$ and $15.87 \%$, 
respectively, which showed a significant influence. For the same seismic wave, the variation trends of the acceleration response in the height direction were consistent under unidirectional and bidirectional loads for both the with and without water conditions. It was indicated that the presence of water would affect the acceleration amplitude, but not significantly affect the effect of the unidirectional and bidirectional seismic loads.

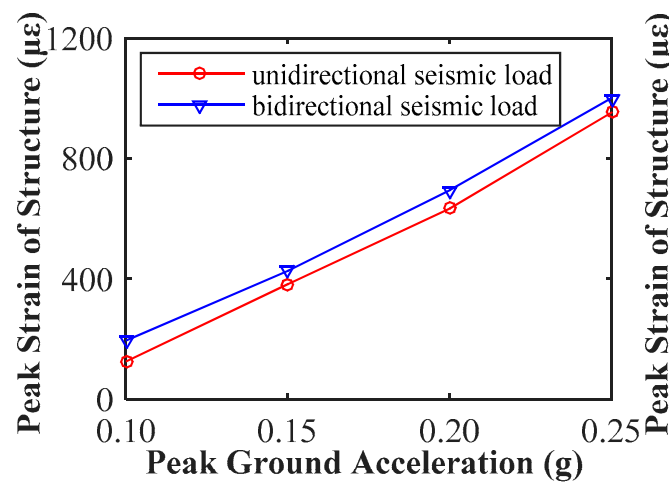

(a)

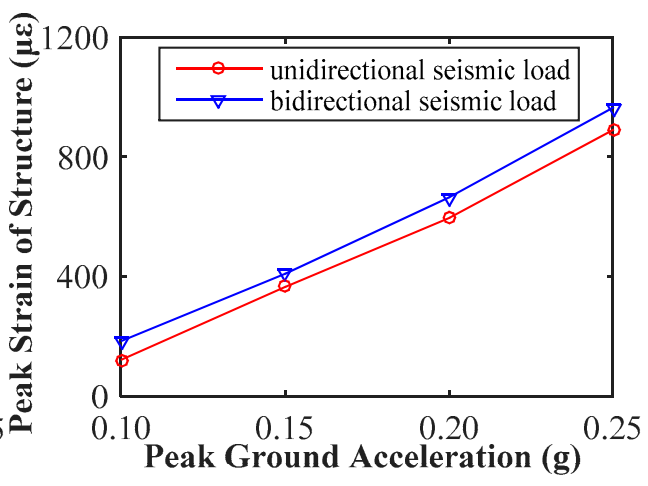

(b)

Figure 19. Structural strain response of the electrical platform under a unidirectional and bidirectional seismic wave. (a) The strain response of S1 and (b) the strain response of S2.

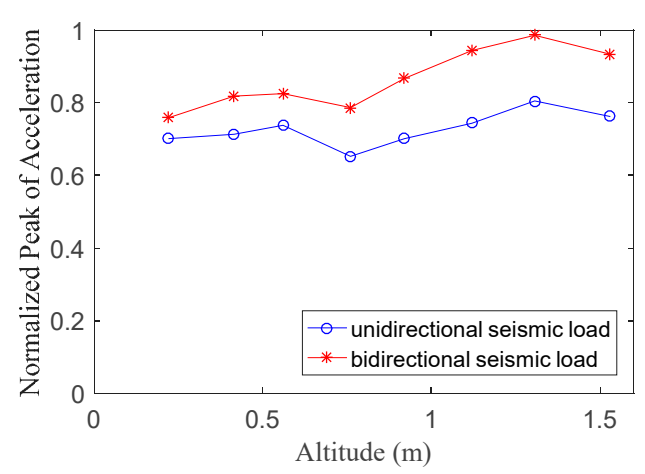

(a)

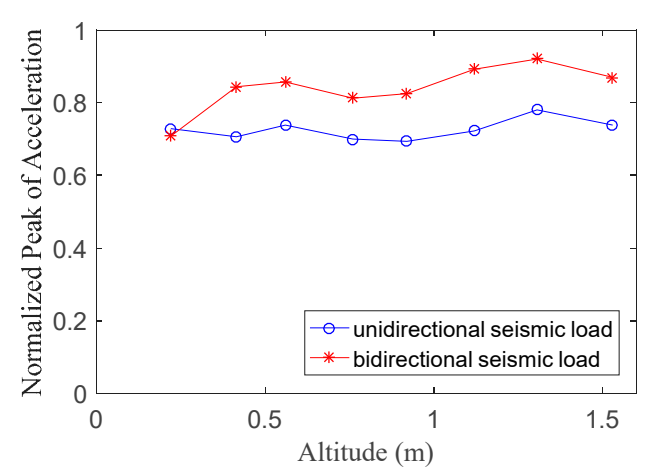

(b)

Figure 20. Structural peak acceleration of the electrical platform under a unidirectional and bidirectional seismic wave. (a) With water and (b) without water.

\subsection{The Trend of Peak Acceleration in the Height Direction}

According to the experiment results of acceleration at different locations, the peak acceleration in the height direction of the platform were obtained. A quadratic polynomial fitting using the least square method was conducted based on measured results at various heights along the pile leg for different seismic waves (see Figure 21). Under the excitation of different seismic waves, the distribution of the peak acceleration of the structure along the height of the platform decreased first and then increased.

Since the bottom of the structure was close to the seismic source, the structural response would follow the input of ground acceleration. However, the top of the platform would produce a certain whipping effect [22,23]. With the joint action of the above two characteristics, the peak acceleration of the structure decreased first and then increased along the height of the platform. Overall, this trend accords with the dynamic response characteristics of a structure under the earthquake load. For an offshore electrical platform of the wind farm, there is a number of important electrical equipment inside the superstructure. Therefore, reducing the whipping effect of the platform is extremely important for the security and stability of the system. 


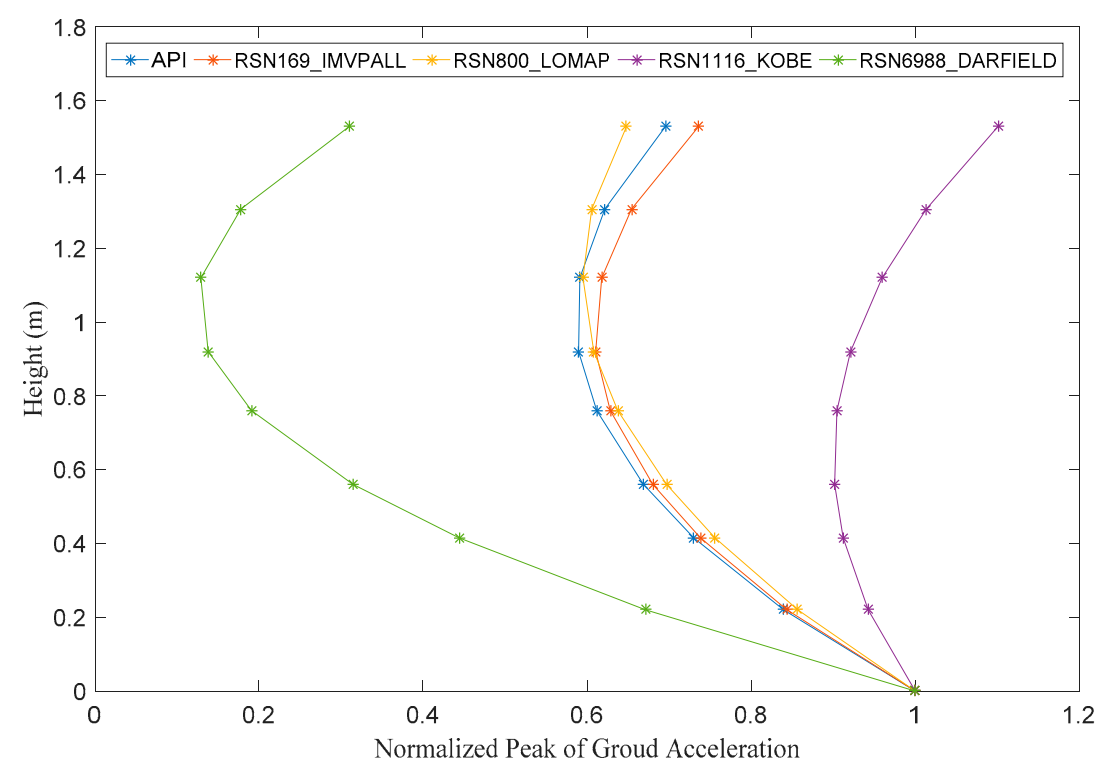

Figure 21. The variation trend of peak acceleration in the height direction of the platform by bidirectional seismic excitation in water.

\section{Conclusions}

In this study, a physical model test was carried out to investigate the dynamic characteristics of a 10,000-ton offshore converter station platform under seismic load. The acceleration response, displacement response and stress response of the offshore electrical platform under the typical direction of seismic action were obtained. The main conclusions were summarized as follows:

(1) The effect of the environment on the structural dynamic characteristics was analyzed. The average damping ratio of the first-order mode of the electrical platform was $5.73 \%$ and $8.68 \%$ in the conditions of with and without water, respectively. The damping ratio of the structure in water was greater than that in the dry mode. Due to the influence of water damping, the peak of the strain and acceleration of the platform structure in water were smaller than those in the dry mode.

(2) The unidirectional and bidirectional seismic excitations had a significant influence on the dynamic characteristics of the structure. At each location of the structure, the peak value of the strain response under bidirectional seismic excitation was generally larger than that under unidirectional seismic excitation. It could be determined that the bidirectional seismic excitation was more dangerous to the structure.

(3) The peak acceleration along the height of the platform structure decreased first and then increased, which showed a typical whipping effect. The dynamic response characteristics of the electrical platform under different seismic loads were generally consistent.

(4) The weak positions of electrical platform structure were found in the experimental study. According to the analyzed data, the strain on the pile leg at the mud surface was the largest. In addition, large strains and stresses were generated at the connections between the superstructure and the jacket. It was indicated that the connections were the weak positions of the electrical platform under a dynamic load.

Author Contributions: Conceptualization, Z.-Z.S. and S.-X.Z.; Data curation, C.-W.B.; Formal analysis, H.-F.Y.; Funding acquisition, S.-X.Z. and G.-H.D.; Investigation, Z.-Z.S. and C.-W.B.; Methodology, C.-W.B. and G.-H.D.; Project administration, S.-X.Z.; Resources, Z.-Z.S., S.-X.Z.; Supervision, S.-X.Z.; Writing-Original draft, C.-W.B.; Writing-Review \& editing, Z.-Z.S., G.-H.D. and H.-F.Y.

Funding: This research was funded by National Natural Science Foundation of China (NSFC), grant nos. 51609035 and 31972843; Research Fund of Power China Huadong Engineering Corporation, project no. KY2018-ZD-03; and Fundamental Research Funds for the Central Universities, project no. DUT18RC(3)076. 
Acknowledgments: The authors acknowledge the technical support from Power China Huadong Engineering Corporation Limited.

Conflicts of Interest: The authors declare no conflict of interest.

\section{References}

1. Sun, X.; Huang, D.; Wu, G. The current state of offshore wind energy technology development. Energy 2012, 41, 298-312. [CrossRef]

2. Harrison, R.; Hau, E.; Snel, H. Large Wind Turbines: Design and Economic; Wiley: Chichester, UK, 2000.

3. Butterfield, S.; Musial, W.; Jonkman, J.M.; Sclavounos, P. Engineering Challenges for Floating Offshore Wind Turbines; National Renewable Energy Laboratory (NREL): Golden, CO, USA, 2007.

4. Snyder, B.; Kaiser, M.J. Ecological and economic cost-benefit analysis of offshore wind energy. Renew. Energy 2009, 34, 1567-1578. [CrossRef]

5. Liu, J.; Thomas, E.; Manuel, L.; Griffith, D.; Ruehl, K.; Barone, M. Integrated system design for a large wind turbine supported on a moored semi-submersible platform. J. Mar. Sci. Eng. 2018, 6, 9. [CrossRef]

6. Bea, R.G.; Akky, M.R.; Audibert, J.M.E. Earthquake response of offshore platforms. J. Struct. Div. 1979, 105, 377-400.

7. Chandrasekaran, S.; Gaurav. Offshore triangular tension leg platform earthquake motion analysis under distinctly high sea waves. Ships Offshore Struct. 2008, 3, 173-184. [CrossRef]

8. Huang, Z.; Foutch, D.A. Effect of hysteresis type on drift limit for global collapse of moment frame structures under seismic loads. J. Earthq. Eng. 2009, 13, 939-964. [CrossRef]

9. Yu, H.; Li, X.; Yang, S. Dynamic analysis method of offshore jack-up platforms in regular and random waves. J. Mar. Sci. Appl. 2012, 11,111-118. [CrossRef]

10. Araki, Y.; Hjelmstad, K.D. Criteria for assessing dynamic collapse of elastoplastic structural systems. Earthq. Eng. Struct. Dyn. 2015, 29, 1177-1198. [CrossRef]

11. Salem, Y.S.; Wang, L.; Aziz, G. Assessment of response modification factor of open steel platform structures subjected to seismic loads. In Facing the Challenges in Structural Engineering; Rodrigues, H., Elnashai, A., Calvi, G., Eds.; Springer: Cham, Switzerland, 2017; pp. 131-143.

12. Failla, G.; Santangelo, F.; Foti, G.; Scali, F.; Arena, F. Response-spectrum uncoupled analyses for seismic assessment of offshore wind turbines. J. Mar. Sci. Eng. 2018, 6, 85. [CrossRef]

13. Zhao, Z.X.; Li, X.; Wang, W.H.; Shi, W. Analysis of dynamic characteristics of an ultra-large semi-submersible floating wind turbine. J. Mar. Sci. Eng. 2019, 7, 169. [CrossRef]

14. Prowell, I.; Elgamal, A.; Uang, C.M.; Luco, E.J.; Romanowitz, H.; Duggan, E. Shake table testing and numerical simulation of a utility scale wind turbine including operational effects. Wind Energy 2014, 17, 997-1016. [CrossRef]

15. Zheng, X.Y.; Li, H.; Rong, W.; Li, W. Joint earthquake and wave action on the monopile wind turbine foundation: An experimental study. Mar. Struct. 2015, 44, 125-141. [CrossRef]

16. Wang, W.H.; Gao, Z.; Moan, T.; Li, X. Model Test and Numerical Analysis of a Multi-Pile Offshore Wind Turbine under Seismic, Wind, Wave and Current Loads. J. Offshore Mech. Arct. Eng. 2016, 139, 031901. [CrossRef]

17. Sadowski, A.J.; Camara, A.; Málaga-Chuquitaype, C.; Dai, K. Seismic analysis of a tall metal wind turbine support tower with realistic geometric imperfections. Earthq. Eng. Struct. Dyn. 2017, 46, 201-219. [CrossRef]

18. Wang, W.H.; Li, X.; Pan, Z.; Zhao, Z.X. Motion control of pentapod offshore wind turbines under earthquakes by tuned mass damper. J. Mar. Sci. Eng. 2019, 7, 224. [CrossRef]

19. Lin, G.; Zhu, T.; Lin, B. Dynamic model test similarity criterion. J. Dalian Univ. Technol. 2000, 40, 1-8. (In Chinese)

20. Chakrabarti, S. Handbook of Offshore Engineering; Elsevier Press: Amsterdam, The Netherlands, 2005.

21. API. Recommended Practice for Planning, Designing, and Constructing Fixed Offshore Platforms-Working Stress Design, 22nd ed.; American Petroleum Institute Recommended Practice 2A-WSD: Washington, DC, USA, 2007. 
22. Yang, L.J.; Liu, D.W.; Guo, Z.L.; Li, J.; Dai, B.H. Engineering mechanics in whipping effect of high-rise building. Appl. Mech. Mater. 2014, 540, 173-176. [CrossRef]

23. Cao, Y.; He, E.; Furrer, M. Whipping effect of the seismic response of unbraced tied arch bridges. IABSE Symp. Rep. 2015, 105, 1-8. [CrossRef] 